\title{
Anticancer and Antitumor Potential of Fucoidan and Fucoxanthin, Two Main Metabolites Isolated from Brown Algae
}

\author{
Soheil Zorofchian Moghadamtousi, ${ }^{1}$ Hamed Karimian, ${ }^{2}$ Ramin Khanabdali, ${ }^{1}$ \\ Mahboubeh Razavi, ${ }^{2}$ Mohammad Firoozinia, ${ }^{1}$ Keivan Zandi, ${ }^{3}$ and Habsah Abdul Kadir ${ }^{1}$ \\ ${ }^{1}$ Biochemistry Program, Institute of Biological Sciences, Faculty of Science, University of Malaya, 50603 Kuala Lumpur, Malaysia \\ ${ }^{2}$ Department of Pharmacy, Faculty of Medicine, University of Malaya, 50603 Kuala Lumpur, Malaysia \\ ${ }^{3}$ Department of Medical Microbiology, Tropical Infectious Disease Research and Education Center (TIDREC), \\ Faculty of Medicine, University of Malaya, 50603 Kuala Lumpur, Malaysia
}

Correspondence should be addressed to Habsah Abdul Kadir; habsah@um.edu.my

Received 15 September 2013; Accepted 1 December 2013; Published 2 January 2014

Academic Editors: L. Eisenbach and U. Naumann

Copyright (C) 2014 Soheil Zorofchian Moghadamtousi et al. This is an open access article distributed under the Creative Commons Attribution License, which permits unrestricted use, distribution, and reproduction in any medium, provided the original work is properly cited.

\begin{abstract}
Seaweed is one of the largest producers of biomass in marine environment and is a rich arsenal of active metabolites and functional ingredients with valuable beneficial health effects. Being a staple part of Asian cuisine, investigations on the crude extracts of Phaeophyceae or brown algae revealed marked antitumor activity, eliciting a variety of research to determine the active ingredients involved in this potential. The sulfated polysaccharide of fucoidan and carotenoid of fucoxanthin were found to be the most important active metabolites of brown algae as potential chemotherapeutic or chemopreventive agents. This review strives to provide detailed account of all current knowledge on the anticancer and antitumor activity of fucoidan and fucoxanthin as the two major metabolites isolated from brown algae.
\end{abstract}

\section{Introduction}

Cancer is a debilitating disease which has afflicted a noticeable proportion of the entire population of the world in all generations [1]. The development of resistance to chemotherapy is considered a major hindrance to treatment of various cancers, as a notable proportion of tumors relapses and develops resistance, eventually resulting in multidrug resistance following exposure to multiple anticancer drugs with prevalent structure and mechanisms of action [2]. Furthermore, ideally anticancer agents should act exclusively against tumor cells; however, numerous chemotherapeutic drugs which are presently being used for cancer patients exhibit considerable adverse side effects on the human body, namely, bleeding, hair loss, diarrhea, and immunosuppression [3]. Hence, discovery of new natural products and metabolites isolated from microorganisms, animals, and plants possessing high efficacy against tumor cells without any toxicity on normal cells is a big leap in scientific researches. Apoptosis as a highly regulated programmed cell death has become a matter of great interest in cancer therapy and oncology because of the high potential of various chemotherapeutic agents in inducing apoptosis in a variety of cancer cells [4]. Thus, screening for natural products capable of inducing apoptosis in cancer cells that can be used alone or in combination with other chemotherapeutic drugs has now been in progress in order to elevate the therapeutic effects and reduce the side effects in cancer therapy [5].

The growing body of experimental and epidemiological evidence supporting the preventive role of marine products in controlling chronic diseases such as cancer has stimulated significant scientific interest in characterizing the active ingredients of marine products. Marine algae as part of diets and traditional remedies in the Eastern Hemisphere are still underexploited plant resources. Due to their unique living environment, algae are rich in bioactive constituents such as phycocyanin, terpenes, fucosterol, and polysaccharides [6]. Extensive beneficial health effects of marine algae have 
highlighted their role as a source of functional ingredients in recent years [7]. A variety of biological activities are attributed to marine algae including neuroprotection, antitumor, anticancer, antioxidant, antiobesity, anti-inflammatory, and antimicrobial, antiangiogenic, and other biological activities [7-10]. Hence, it is clearly documented that in vivo and in vitro studies with marine algae compounds continue to be extremely active in recent history [11].

Brown algae or Phaeophyceae characterized by their natural pigments form an important group of marine algae [12]. Different types of brown algae including wakame (Undaria pinnatifida), kombu (Laminaria japonica), and hijiki (Sargassum fusiforme) are staples in East Asians diet, especially Japan and Korea [13]. Viscous components including gepsin, porphyran, alginic acid, and oligosaccharide protecting the seaweed from invasion of bacteria that are involved in different health benefits of brown algae are clear illustrations of the importance and diversity of the constituents isolated from Phaeophyceae [14]. Thus, the active constituents of brown algae have been subjected to a variety of studies in recent years. This review briefly describes the antitumor potential of various brown algae species and summarizes the antitumor activity of fucoidan and fucoxanthin as the two main metabolites isolated from brown algae and the mechanisms underlying this activity.

\section{Antitumor Activity of Brown Algae}

The extensive research on the crude extracts of various brown algae isolated from different marine environments against different cancer cell lines shows promising anticancer potential. The study on antiproliferative activity of crude extracts of ten Phaeophyta species isolated from Brittany coasts against three human cancers, human leukaemic T cell lymphoblast (Jurkat), human Burkitt's lymphoma (Daudi), and human chronic myelogenous leukaemia (K562) cells, showed strong antitumor potential of Sargassaceae species, Dictyota dichotoma, and Desmarestia ligulata [15]. The crude methanol extract of the marine algae isolated from Aegean Shores of Turkey demonstrated strong inhibitory effect (90\%) of Padina pavonica and Cystoseira mediterranea brown algae against human breast adenocarcinoma (MCF-7) and human prostate cancer cells (DU 145, PC-3, and LNCaP) [16]. The in vitro investigation on the enzymatic extract of Ecklonia cava together with its crude polyphenolic and polysaccharide fractions showed antiproliferative activity against murine colon cancer cell line (CT-26), human leukemia (THP1), mouse melanoma (B-16), and human leukemia (U-937) cells. The polyphenolic extract showed the strongest activity against CT-26 cells $\left(\mathrm{IC}_{50}=5.1 \mu \mathrm{g} / \mathrm{mL}\right)$ through apoptotic cell demise according to the nuclear staining experiment [17].

The in vivo studies on tumor suppressive activity of brown algae signified the importance of the in vitro anticancer potential of these seaweeds for cancer therapy. The investigation on the antitumor activity of the powdered tissue from 21 species of air-dried brown algae against Ehrlich carcinoma in mice showed significant inhibitory effect of $S$. ringgoldianum (46.5\% inhibition), L. japonica (57.6\%), Lessonia nigrescens (60.0\%), and Scytosiphon lomentaria (69.8\%) after oral administration of seaweed powder $(1600 \mathrm{mg} / \mathrm{kg}$ of body weight) for 28 days [18]. In another study, wakame ( $U$. pinnatifida), the most popular edible seaweed in Japan, exhibited marked inhibitory effect against 7,12-dimethylbenz(a)anthracene (DMBA)-induced rat mammary tumor associated with apoptosis. The results suggested induction of apoptosis via expression of transforming growth factor (TGF)- $\beta$ through transportation of iodine from serum into mammary tissues [19]. The aqueous extract isolated from the sporophyll of $U$. pinnatifida (Mekabu) also showed strong in vivo and in vitro antitumor activity against breast cancer cells. It indicated significant antiproliferative activity against three kinds of human breast cancer cells, namely, MCF-7, T47D, and MDA-MB-231, through an induction of apoptosis. Mekabu solution when used in daily drinking water revealed significant suppressive activity on rat mammary carcinogenesis, without any toxicity to normal cells. The inhibitory effect of Mekabu proved to be stronger than some of the widely used chemotherapeutic agents against breast cancer [20]. This remarkable anticancer and antitumor potential shown by various brown algae led scientists to isolate a variety of constituents and metabolites involved in the respective activities. The sulfated polysaccharide of fucoidan and carotenoid of fucoxanthin were found to be the most important active metabolites of brown algae as potential chemotherapeutic or chemopreventive agents.

\section{Fucoidan}

Fucoidan is a class of sulfated polysaccharides enriched with fucose in the extracellular matrix of brown algae. Fucoidans have demonstrated various biological activities including antiviral, anti-inflammatory, anticoagulant, antiangiogenic, immunomodulatory, and anti-adhesive activity [21, 22]. Due to possible differences in the chemical structure, the biological effects of this compound proved to be noteworthy depending on the species from which it is isolated (Figure 1) [22]. Thereby, fucoidan as a fucose-containing sulfated heteropolysaccharide is not uniform and its structure highly differs depending on the species source of isolation [23]. Furthermore, the constituents of fucoidan also differ with the species by small proportions of D-mannose, D-xylose, Dgalactose, and uronic acid. Industrial scale of fucoidan has been prepared to be used as an additive to drinks, health foods, and cosmetics in Japan [24].

In the 1980s, the study of fucoidan in xenograft mouse models elicited antitumor and antimetastatic effects which attracted the attention of researchers in conducting more detailed studies on the antitumor and anticancer potential of this marine product $[25,26]$. The antitumor activity of 31 polysaccharide fractions isolated from $S$. thunbergii when evaluated against Ehrlich carcinoma transplanted in mice revealed the antitumor potential of fucoidan or Lfucan containing roughly $30 \%$ sulfate ester groups per fucose residue, less than $2 \%$ protein, and approximately $10 \%$ uronic acid [27]. The variety of research on fucoidan revealed several critical factors involved in the marked antitumor potential of this polysaccharide. 


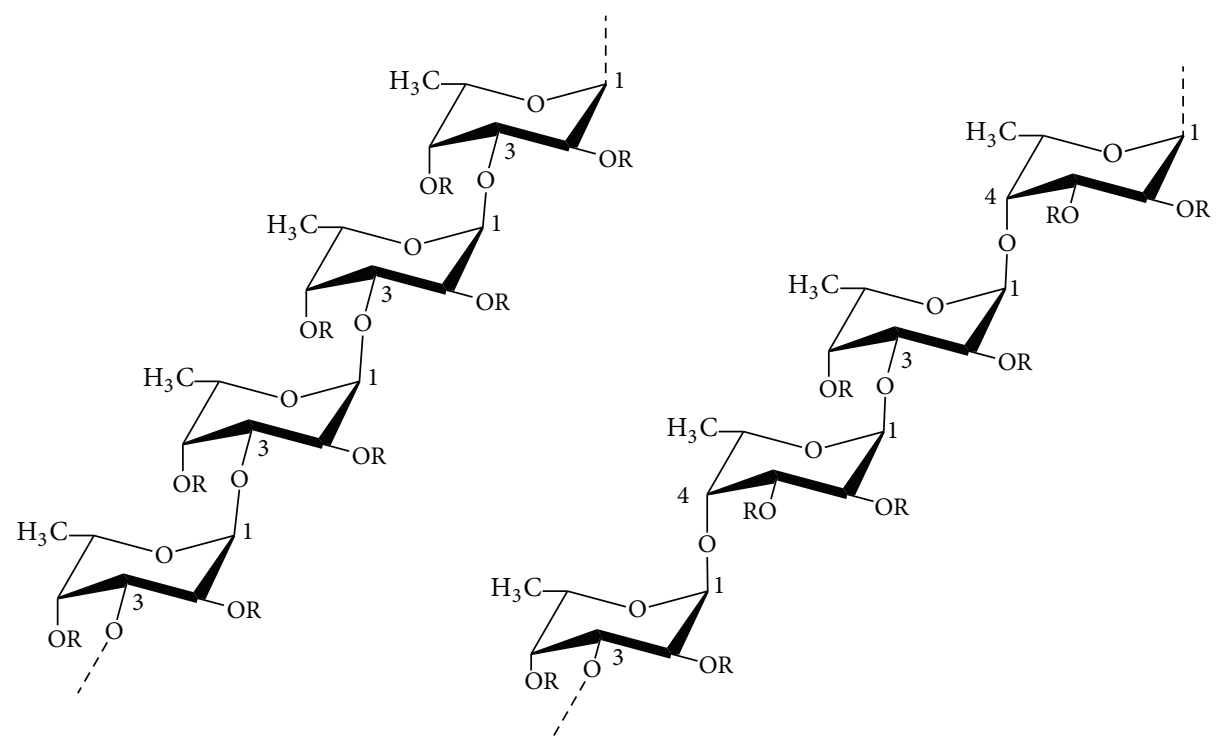

FIgURE 1: Two different types of homofucose backbone chains in fucoidans isolated from brown seaweed. R groups depict the potential places for attachment of noncarbohydrate (sulfate and acetyl groups) and carbohydrate ( $\alpha$-L-fucopyranose and $\alpha$-D-glucuronic acid) substituents.

The antiangiogenic activity of fucoidan isolated from Fucus vesiculosus explained, at least in part, the mechanism of the antitumor potency. Further study showed that fucoidan possessed strong inhibitory activity on tube formation following migration of human umbilical vein endothelial cells (HUVEC) and its chemical oversulfation increased the inhibitory potential. Both natural as well as oversulfated fucoidans remarkably reduced the chemotactic and mitogenic roles of the vascular endothelial growth factor 165 $\left(V_{E G F}{ }_{165}\right)$ on HUVEC due to antagonistic effect on the binding of $\mathrm{VEGF}_{165}$ to its cell surface receptor [28]. However, oversulfated fucoidan revealed stronger suppressive effect, suggesting a critical role of the number of sulfate groups in the fucoidan molecule.

Antitumor activity of fucoidan demonstrated antiproliferative activity in Lewis lung carcinoma and B16 melanoma in mice. According to their results, the number of sulfate groups in the fucoidan molecule is directly correlated with the potency of its anti-angiogenic and thereby antitumor effects [28]. In another study, enzyme-digested fucoidan extracted from Mozuku seaweed Cladosiphon novae-caledoniae Kylin revealed significant anti-angiogenic activity on human uterine carcinoma HeLa cells by reducing the expression and secretion of VEGF leading to attenuation of vascular tubules formation of tumor cells. Fucoidan also significantly reduced the invasion potential of human fibrosarcoma HT1080 cells possibly through suppression of the matrix metalloproteinases (MMPs) MMP-2/9 activities. It is suggested that these effects may be explained, at least partially, by the antioxidative potential of fucoidan extracts [29].

Another factor involved in the antitumor activity of fucoidan proved to be its ability to enhance the immune response. The study on fucoidan extracted from $S$. thunbergii revealed significant inhibitory effect against the growth of Ehrlich ascites carcinoma in mice $(20 \mathrm{mg} / \mathrm{kg}$ per day) without any sign of toxicity. The results showed enhancement in the immune response of mice by increasing the phagocytosis activity of macrophages [30]. Prolonged survival rate of P-388 tumor-bearing mice treated with fucoidan isolated from the sporophyll of $U$. pinnatifida was associated with roughly 2 -fold elevation in the IFN-gamma produced by $\mathrm{T}$ cells. This result suggested the involvement of IFN-gammaactivated NK cells in the antitumor activity of fucoidan [31]. In another in vivo study, single and repeated administration of fucoidan from $F$. evanescens $(10 \mathrm{mg} / \mathrm{kg}$ body weight) indicated antimetastatic and antitumor activity in C57BL/6 mice with transplanted Lewis lung adenocarcinoma. Furthermore, treatment with fucoidan at a dose of $10 \mathrm{mg} / \mathrm{kg}$ body weight potentiated the antimetastatic effect of cyclophosphamide [32]. The chemoresistance in non-small-cell human bronchopulmonary carcinoma (NSCLC-N6) cells was significantly reduced by fucoidan extracted from Ascophyllum nodosum with an arrest observed in the $\mathrm{G}_{1}$ phase of the cell cycle. An in vivo study on the NSCLC-bearing nude mice also revealed the antitumor effect of fucoidan at subtoxic doses [33].

Induction of apoptosis as a critical factor in cancer therapy and oncology also contributed to significant antitumor activity of this sulfated polysaccharide. Cytotoxicity activity of fucoidan from $F$. vesiculosus demonstrated antiproliferative activity on human lymphoma HS-Sultan cell line via apoptosis induction accompanied with caspase-3 activation. The partial inhibition of apoptosis by pretreatment with pan-caspase inhibitor, Z-VAD-FMK, suggested the involvement of caspase-independent proapoptotic pathways, while the decrease in the mitochondrial membrane potential in HS-Sultan cells after $24 \mathrm{~h}$ treatment with fucoidan demonstrated the role of mitochondrial pathway. Furthermore, reduced phosphorylation of ERK (extracellular signal-regulated kinase) and GSK (glycogen synthase kinase) observed 
after $24 \mathrm{~h}$ treatment with fucoidan $(100 \mu \mathrm{g} / \mathrm{mL})$ also suggested that the ERK pathways are involved in the induced apoptosis in human HS-Sultan cells [34]. Fucoidan isolated from C. okamuranus (containing the highest percentage of fucoidan among the brown algae) was found to reduce the damage induced by anticancer drug 5-fluorouracil (5FU) in Hs 677.st normal stomach cells, despite minimum inhibition on the original activity of 5-FU in stomach cancer cell line (MKN45). Further study of fucoidan demonstrated antiproliferative activity on stomach cancer cells without any effects on normal stomach cells [35]. According to a more recent study, fucoidan isolated from C. okamuranus inhibited the proliferation of MCF-7 cells in a time- and dosedependent manner without any effect on the viability of normal human mammary epithelial cells. Their results indicated that fucoidan induced apoptosis via caspase-8-dependent pathway which was characterized by chromatin condensation, internucleosomal DNA fragmentation, cleavage of poly(ADP ribose) polymerase, and activation of caspase-7, caspase-8, and caspase-9. Fucoidan was found to decrease cytosolic Bax and significantly elevate cytosolic cytochrome c [36]. The critical role of caspase- 8 in fucoidan-induced apoptosis was indicated via inhibition of caspase- 8 by the specific caspase- 8 inhibitor z-ITED-FMK which resulted in the inactivation of caspase-7, caspase- 8 , and caspase- 9 and a series of changes in cytochrome $\mathrm{c}$, Bid, and Bax expression and thereby suppression in the cytotoxicity of fucoidan [36]. Since digestive enzymes in human small intestine are not able to hydrolyze fucoidan and its consumption can lead to an elevation in the concentration of luminal fucoidan within the large intestine, it may be a potent chemopreventive agent for colon cancer [37]. HT-29 and HCT116 (human colon cancer cells) treated with fucoidan $(0-20 \mu \mathrm{g} / \mathrm{mL})$ extracted from $F$. vesiculosus demonstrated a dose-dependent antiproliferative effect and induction of apoptosis mediated through both the mitochondria-mediated and death receptor-mediated pathways. In addition, their results indicated that fucoidan induced apoptosis via the death receptor-mediated pathway through both the direct and indirect activation of caspase3 in HT-29 cells. These results indicated that fucoidan is a potentially useful therapeutic agent for colon cancer by simultaneous activation of different apoptotic factors and pathways [38]. In human leukemia cell line (U937), the antiproliferative activity by oversulfated fucoidan was more potent compared to the native fucoidan isolated from $C$. okamuranus that greatly highlighted the role of sulfate groups in the fucoidan molecule. The results indicated that oversulfated fucoidan induced apoptosis in U937 cells through caspase-3 and caspase-7 activation-dependent pathway [24]. Furthermore, fucoidan extracted from $F$. vesiculosus induced apoptosis in HCT-15 cells $\left(\mathrm{IC}_{50}=34 \mu \mathrm{g} / \mathrm{mL}\right)$ via activation of pro-caspase- 9 and pro-caspase- 3 and downregulation of Bcl-2. Additionally, fucoidan-induced apoptosis was accompanied by the strong activation of $\mathrm{p} 38$ kinase and ERK and the inhibition of the phosphatidylinositol 3-kinase (PI3K)/Akt signal pathway in HCT-15 cells [39]. Fucoidan isolated from the sporophyll of Korean brown seaweed U. pinnatifida which is chemically defined as $O$-acetylated sulphated galactofucan also exhibited antitumor activity in A549 (alveolar carcinoma), HepG2 (hepatocellular carcinoma), HeLa (cervical carcinoma), and PC-3 cells, in a similar pattern to that of commercial fucoidan [40].

Interaction of tumor cells with platelets was found to be a critical factor in the initial steps favoring tumor metastasis [41]. Fucoidan isolated from L. saccharina, L. digitata, F. serratus, F. distichus, and F. vesiculosus demonstrated roughly $80 \%$ reduction in the adhesion of MDA-MB 231 tumor cells to human platelets in vitro. However, fucoidan extracted from $A$. nodosum and $F$. evanescens revealed $66 \%$ and $78 \%$ inhibitory effect, respectively [42]. The results proved the potential use of fucoidans for development of new drugs against tumor progression. It also proved the influence of fucoidan origin on their composition and thereby biological activities. Activation of the intrinsic and extrinsic pathways of apoptosis, increase in the immune response, suppression of angiogenesis, and reduction in the adhesion of tumor cells to human platelets are suggested as mechanisms responsible for significant antitumor activity of fucoidan (Table 1).

\section{Fucoxanthin}

Carotenoids as a group of natural pigments with more than 600 members possess a variety of biological activities including radical scavenging, immunomodulation, singlet oxygenquenching activity, and other pharmacological effects [43]. Carotenoids include two main subclasses of nonpolar hydrocarbon carotenes and polar compounds named xanthophylls. One well known example of xanthophylls for anticancer activity is fucoxanthin [44]. Fucoxanthin ( $3^{\prime}$-acetoxy-5,6epoxy-3,5' -dihydroxy- $6^{\prime} 7^{\prime}$-didehydro-5,6,7,8,5, $6^{\prime}$-hexahydro- $\beta \beta$-caroten-8-on) with a unique carotenoid structure including an allenic band and a 5,6-monoepoxide is a major nonprovitamin A carotenoid isolated from brown seaweed [13]. This orange-colored pigment carotenoid contributes more than $10 \%$ of the total carotenoids in nature, particularly in the marine ecosystem, albeit, besides brown algae, fucoxanthin was also isolated from diatoms (Bacillariophyta) [45].

Free radical scavenging activity of fucoxanthin was suggested to be the mechanism underlying its anticancer effect. An in vitro study by Okuzumi and colleagues [46] on the inhibitory activity of fucoxanthin against GOTO (human neuroblastoma) cell line showed $68 \%$ inhibitory effect at $10 \mu \mathrm{g} / \mathrm{mL}$ concentration after 3 days. A decrease in the expression of $\mathrm{N}$-myc gene after $4 \mathrm{~h}$ treatment of fucoxanthin $(10 \mu \mathrm{g} / \mathrm{mL})$ and cell cycle arrest in the $\mathrm{G}_{0}-\mathrm{G}_{1}$ phase were associated with the growth reduction in GOTO cells [46]. In another in vivo study on duodenal carcinogenesis induced by $\mathrm{N}$-ethyl- $\mathrm{N}^{\prime}$-nitro-N-nitrosoguanidine in mice revealed that consumption of drinking water treated with $0.005 \%$ fucoxanthin in dimethyl sulfoxide (DMSO) for 12 weeks significantly reduced the average number of tumors per mice and the percentage of tumor-bearing mice compared to the control group [47]. Further study demonstrated the inhibitory effect of fucoxanthin on liver tumorigenesis in $\mathrm{C} 3 \mathrm{H} / \mathrm{He}$ male mice and two-stage skin carcinogenesis in ICR mice [48]. Chemopreventive activity of fucoxanthin 
TABle 1: Anticancer and antitumor activity of fucoidans isolated from brown algae.

\begin{tabular}{|c|c|c|}
\hline Source of isolation & Type of activity and possible mechanisms & References \\
\hline S. thunbergii & Growth inhibitory activity in Ehrlich ascites carcinoma in mice & {$[30]$} \\
\hline S. thunbergii & Antitumor effect in mice with Ehrlich carcinoma transplanted & {$[27]$} \\
\hline A. nodosum & $\begin{array}{l}\text { In vivo and in vitro inhibitory effect against NSCLC-N6, non-small-cell human } \\
\text { bronchopulmonary carcinoma }\end{array}$ & {$[33]$} \\
\hline U. pinnatifida & Antitumor effect against P-388 tumor-bearing mice & {$[31]$} \\
\hline F. vesiculosus & Elevation of antiangiogenic and antitumor activities by oversulfation & {$[28]$} \\
\hline C. novae-caledoniae Kylin & Anti-angiogenic activity on human uterine carcinoma HeLa cells & {$[29]$} \\
\hline F. vesiculosus & $\begin{array}{l}\text { Induction of apoptosis in human lymphoma HS-Sultan cell line associated with } \\
\text { caspase- } 3 \text { activation and downregulation of ERK pathway }\end{array}$ & {$[34]$} \\
\hline C. okamuranus & Growth inhibitory activity on stomach cancer cell line of MKN45 & {$[35]$} \\
\hline F. evanescens & $\begin{array}{l}\text { Enhancement in etoposide induced caspase-dependent cell death pathway on } \\
\text { MT-4, human malignant lymphoid cell lines }\end{array}$ & {$[42]$} \\
\hline F. evanescens & $\begin{array}{l}\text { Antimetastatic and antitumor activity in } \mathrm{C} 57 \mathrm{Bl} / 6 \text { mice with transplanted Lewis } \\
\text { lung adenocarcinoma }\end{array}$ & {$[32]$} \\
\hline $\begin{array}{l}\text { L. saccharina, L. digitata, } F \text {. } \\
\text { vesiculosus, F. serratus, } F \text {. } \\
\text { distichus, F. evanescens, and } \\
\text { A. nodosum }\end{array}$ & Blocked adhesion of MDA-MB-231 breast carcinoma cell to platelets & {$[22]$} \\
\hline C. okamuranus & $\begin{array}{l}\text { Induction of apoptosis in U937, human leukemia cells, by oversulfated form of } \\
\text { fucoidan }\end{array}$ & {$[24]$} \\
\hline C. okamuranus & $\begin{array}{l}\text { Induction of apoptosis in MCF-7 cells, human breast cancer, via } \\
\text { caspase-8-dependent pathway }\end{array}$ & {$[36]$} \\
\hline F. vesiculosus & Induction of apoptosis in HCT-15, colon carcinoma cells & {$[39]$} \\
\hline F. vesiculosus & $\begin{array}{l}\text { Induction of apoptosis in HT- } 29 \text { and HCT116, human colon cancer cells, via both } \\
\text { intrinsic and extrinsic pathways }\end{array}$ & {$[38]$} \\
\hline U. pinnatifida & Antitumor activity against PC-3, HepG2, A549, and HeLa cancer cells & [40] \\
\hline
\end{tabular}

isolated from Hijikia fusiforme on the development of putative preneoplastic aberrant crypt foci (ACF) in the colon of $\mathrm{B}_{6} \mathrm{C} 3 \mathrm{~F}_{1}$ male mice induced by 1,2-dimethylhydrazine dihydrochloride proved the potential of fucoxanthin as a chemopreventive agent against colon carcinogenesis. Treatment with fucoxanthin $(0.01 \%)$ in the drinking water of the mice for 7 weeks significantly decreased the ACF/mouse from 63.3 for the control group to 47.1 value [49]. These promising antitumor results shown by fucoxanthin warranted the various detailed investigations for determining the exact mechanisms underlying such a strong antitumor potential.

Antitumor activity of fucoxanthin isolated from U. pinnatifida against human leukemic HL-60 cells showed significant inhibitory effect on HL-60 proliferation in a dosedependent manner. Treatment of HL-60 with $11.3 \mu \mathrm{M}$ and $45.2 \mu \mathrm{M}$ of fucoxanthin for $24 \mathrm{~h}$ reduced the viability to $46.0 \%$ and $17.3 \%$ compared to the control value, respectively. Induction of DNA fragmentation by fucoxanthin implied apoptosis for reduced proliferation of HL-60 cells [50]. The cytotoxicity of fucoxanthin isolated from U. pinnatifida was investigated in three lines of human prostate cancer cells, namely, PC-3, DU 145, and LNCaP. According to their results, $72 \mathrm{~h}$ treatment with fucoxanthin $(20 \mu \mathrm{mol} / \mathrm{L})$ significantly reduced cell viability to $9.8 \%$ for LNCaP, 5.0\% for DU 145, and 14.9\% for PC3. Induction of DNA fragmentation by fucoxanthin detected by TUNEL assay suggested that apoptosis is responsible for the reduction in cell viability of human prostate cancer cells [51]. Fucoxanthin was found to induce apoptosis in PC-3 cells via caspase- 3 activation associated with reduction in the expression of $\mathrm{Bax}$ and $\mathrm{Bcl}-2$ proteins without any change in the protein level of $\mathrm{Bcl}-\mathrm{X}_{\mathrm{L}}$. This unique response in the expression of Bcl-2 family proteins in PC-3 cells suggested a mechanism different from the other apoptosis-inducing agents which modulate the ratios of $\mathrm{Bcl}-2$ and $\mathrm{Bcl}-\mathrm{X}_{\mathrm{L}}$ protein levels with the expression of Bax protein. After $48 \mathrm{~h}$ treatment with fucoxanthin $(20 \mu \mathrm{M})$, the level of apoptotic cells characterized by DNA fragmentation showed an increased percentage of hypodiploid cells, morphological changes, and cleavages of caspase- 3 and PARP (poly(ADP-ribose) polymerase) escalated to $30 \%$ [52]. In another study, fucoxanthin isolated from $U$. pinnatifida revealed a remarkable inhibitory activity against the viability of human colon cancer cell lines (HT-29, DLD-1, and Caco-2) through apoptosis which was evidenced by DNA fragmentation. Treatment with $22.6 \mu \mathrm{M}$ of fucoxanthin in Caco- 2 cells increased DNA fragmentation effect by 10 -fold compared to the control which was partially inhibited by caspase inhibitor Z-VAD-fmk. Fucoxanthin also suppressed the level of $\mathrm{Bcl}-2$ protein revealed by western blot analysis. Effective decrease in Caco- 2 cell viability caused by a combined treatment of $10 \mu \mathrm{M}$ of troglitazone as a specific 

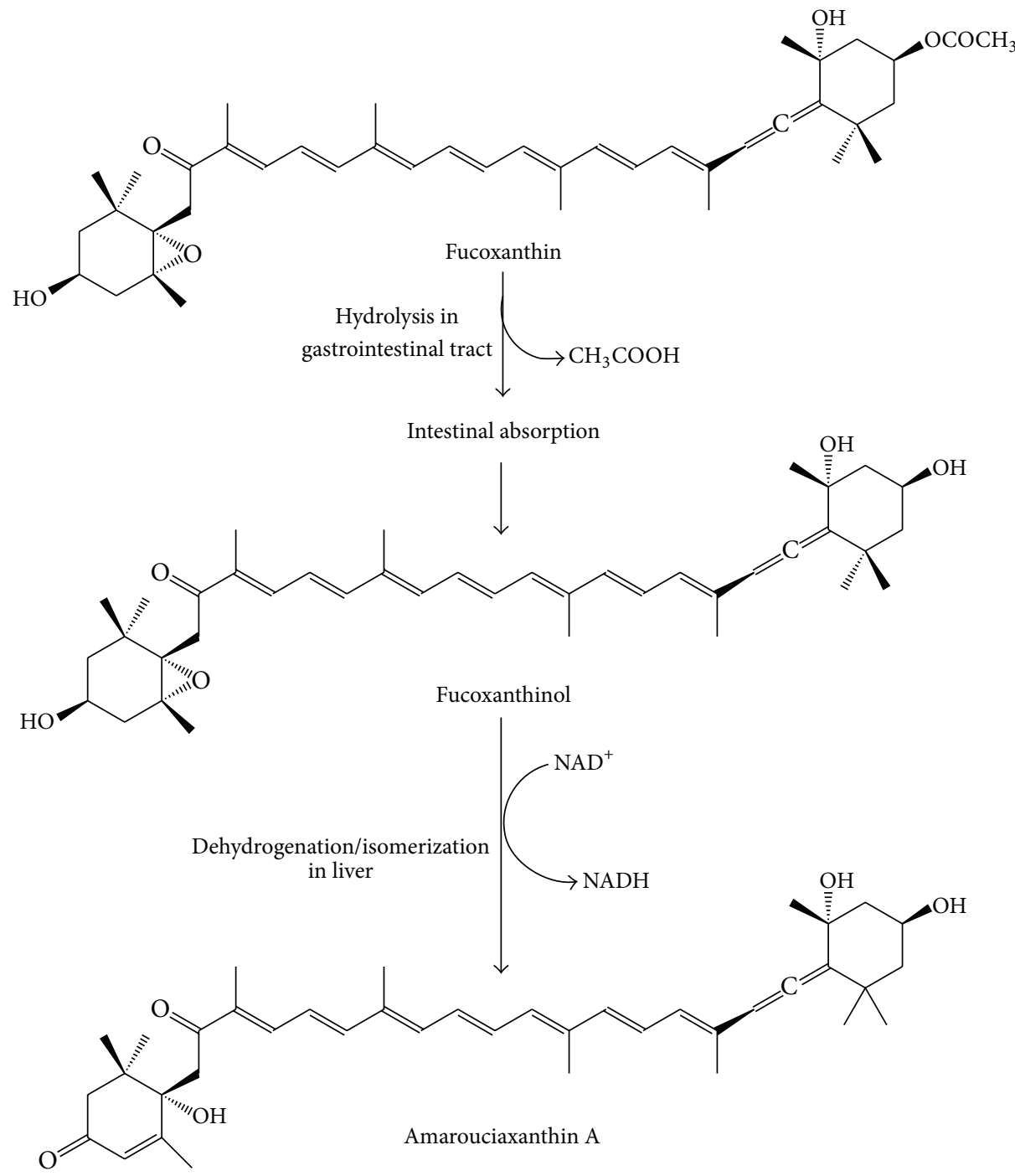

FIGURE 2: Proposed metabolic pathway of dietary fucoxanthin in mammals.

ligand for peroxisome proliferator-activated receptor (PPAR) $\gamma$ and $3.8 \mu \mathrm{M}$ of fucoxanthin demonstrated potential complementary chemopreventive or chemotherapeutic activity of fucoxanthin on colon cancer [53].

The metabolic fate of fucoxanthin in mice and HepG2 cells revealed its conversion into two metabolites, fucoxanthinol and amarouciaxanthin A. It is suggested that prior to absorption in the intestine, fucoxanthin is hydrolyzed into fucoxanthinol in the gastrointestinal tract which is later converted to amarouciaxanthin $\mathrm{A}$ in the liver. The proposed metabolic pathway of dietary fucoxanthin in mammals is presented in Figure 2. In another study, fucoxanthin, fucoxanthinol, and amarouciaxanthin A demonstrated $\mathrm{IC}_{50}$ values of $3.0 \mu \mathrm{M}, 2.0 \mu \mathrm{M}$, and $4.6 \mu \mathrm{M}$, respectively, suggesting that fucoxanthinol was the most active metabolite of fucoxanthin against PC-3 cells [13]. Further in vitro study of fucoxanthin isolated from $U$. pinnatifida $(5 \mu \mathrm{M})$ showed significant inhibitory effect against HCT116 cells, although it did not significantly reduce the growth of HUC-Fm (human male umbilical cord fibroblast) and MRC-5 (human normal embryonic lung fibroblast) as normal cells. The results suggested the safety of fucoxanthin against normal cells at $5 \mu \mathrm{M}$ concentration which is cytotoxic against cancer cell lines. Nevertheless, at the concentration of $10 \mu \mathrm{M}$, fucoxanthin exhibited a significant dose-dependent growth reduction in HCT-116 cells as well as normal cells, HUC-Fm, and MRC5 [54]. It also showed significant inhibitory effect on the proliferation of WiDr cells after $24 \mathrm{~h}$ in a dose-dependent manner.

Mechanistically, fucoxanthin against HCT-116 and WiDr cells demonstrated cell cycle arrest at $G_{0} / G_{1}$ phase via upregulation of $\mathrm{p} 21^{\text {WAF1/Cip1 }}$ (cyclin-dependent kinase inhibitor protein) as a mechanism for the antiproliferative and apoptosis inducing potential of fucoxanthin which may be related to the antitumorigenic effect [44]. Treatment with fucoxanthin $(25 \mu \mathrm{M})$ after $24 \mathrm{~h}$ also reduced the phosphorylation of the 
TABle 2: Anticancer and antitumor activity of fucoxanthin and its metabolites isolated from brown algae.

\begin{tabular}{|c|c|c|c|}
\hline Type & Source & Type of activity & References \\
\hline Fucoxanthin & U. pinnatifida & $\begin{array}{l}\text { Inhibitory effect against growth of GOTO cells, a human } \\
\text { neuroblastoma cell line }\end{array}$ & {$[46]$} \\
\hline Fucoxanthin & U. pinnatifida & $\begin{array}{l}\text { Inhibitory effect against duodenal carcinogenesis induced by } \\
\mathrm{N} \text {-ethyl-N }{ }^{\prime} \text {-nitro-N-nitrosoguanidine in mice }\end{array}$ & {$[47]$} \\
\hline Fucoxanthin & U. pinnatifida & Suppression of skin and liver carcinogenesis in vivo & {$[48]$} \\
\hline Fucoxanthin & H. fusiforme & $\begin{array}{l}\text { Reduced development of putative preneoplastic aberrant crypt foci } \\
\text { (ACF) in colon of mice }\end{array}$ & {$[49]$} \\
\hline Fucoxanthin & U. pinnatifida & $\begin{array}{l}\text { Inhibitory effect against the proliferation of HL- } 60 \text {, human leukemia } \\
\text { cell line, through apoptosis }\end{array}$ & {$[50]$} \\
\hline Fucoxanthin & U. pinnatifida & $\begin{array}{l}\text { Decreased cell viability in prostate cancer cell lines of PC-3, DU 145, } \\
\text { and LNCaP }\end{array}$ & {$[51]$} \\
\hline Fucoxanthin & U. pinnatifida & $\begin{array}{l}\text { Inhibitory effect against viability of human colon cancer cell lines, } \\
\text { HT-29, DLD-1, and Caco-2, through apoptosis }\end{array}$ & {$[53]$} \\
\hline $\begin{array}{l}\text { Fucoxanthinol, } \\
\text { amarouciaxanthin A }\end{array}$ & $\begin{array}{l}\text { Metabolites of } \\
\text { fucoxanthin }\end{array}$ & Inhibitory effect against PC-3, prostate cancer cell line & {$[13]$} \\
\hline Fucoxanthin & U. pinnatifida & Inhibitory effect against HCT116, human colorectal adenocarcinoma & {$[54]$} \\
\hline Fucoxanthin & U. pinnatifida & Induction of apoptosis in PC-3 cells via caspase- 3 activation & {$[52]$} \\
\hline Fucoxanthin & L. japonica & $\begin{array}{l}\text { Cell cycle arrest at } \mathrm{G}_{0} / \mathrm{G}_{1} \text { phase in human colon cancer cells induced } \\
\text { by upregulation of } \mathrm{p} 21^{\mathrm{WAFI} / \mathrm{Cipl}}\end{array}$ & {$[44]$} \\
\hline Fucoxanthin & Unmentioned & $\begin{array}{l}\text { Induction of G1 arrest and GADD } 45 \text { A gene expression in HepG } 2 \text { and } \\
\text { DU145 cells }\end{array}$ & {$[55]$} \\
\hline Fucoxanthin & U. pinnatifida & Antiadult T-cell leukemia activity & {$[45]$} \\
\hline Fucoxanthinol & $\begin{array}{l}\text { Metabolites of } \\
\text { fucoxanthin }\end{array}$ & In vivo and in vitro antiadult $\mathrm{T}$-cell leukemia activity & {$[45]$} \\
\hline Fucoxanthinol & L. japonica & $\begin{array}{l}\text { Inhibitory effect against HepG2, human hepatic carcinoma, } \\
\text { associated with downregulation of cyclin D }\end{array}$ & {$[56]$} \\
\hline Fucoxanthin & U. pinnatifida & $\begin{array}{l}\text { Induction of cell cycle arrest in G2/M phase and apoptosis in } \\
\text { MGC- } 803 \text { cells, human gastric adenocarcinoma }\end{array}$ & {$[58]$} \\
\hline
\end{tabular}

retinoblastoma protein $(\mathrm{Rb})$ at Serine $807 / 811$ and Serine 780 in WiDr cells which is a crucial factor for the progression of $\mathrm{G}_{1}$ phase and the transition of $\mathrm{G}_{1}$ to $\mathrm{S}$ phase. Nonetheless, at a concentration of $25 \mu \mathrm{M}$, no change was reported in the protein levels of the cyclin-dependent kinase (cdk) 4 and D-types of cyclin, whose complexes are attributed to the phosphorylation of $\mathrm{Rb}$ at these sites, while treatment at concentrations higher than $50 \mu \mathrm{M}$ of fucoxanthin reduced their protein expression. These molecular changes led to apoptosis in colon cancer cells at concentrations higher than $50 \mu \mathrm{M}$ after $48 \mathrm{~h}$ treatment [44]. Investigation of the precise mechanism for the inhibitory activity of fucoxanthin against prostate cancer DU145 and human hepatocellular carcinoma $\mathrm{HepG}_{2}$ cell lines when assessed by DNA microarray and flow cytometry revealed induction of $\mathrm{G}_{1}$ arrest and GADD 45A gene expression, a cell cycle related gene, without inducedapoptosis. Additionally, fucoxanthin also induced GADD153 and PIM1 (coding a Ser/Thr kinase) expressions in HepG2 and DU145 cells, although CYP1A1, an activator of procarcinogens, was significantly expressed in HepG2 cells [55]. In addition, the study on the molecular mechanism of the inhibitory effect of fucoxanthin $(25 \mu \mathrm{M})$ against HepG2 cells revealed induction of cell cycle arrest at $G_{0}-G_{1}$ phase. This inhibitory effect was associated with suppression in the phosphorylation of $\mathrm{Rb}$ at Serine780 and downregulation in the kinase activity of cyclin D and cdk4 complex, which is responsible for the phosphorylation of $\mathrm{Rb}$ at Ser780 site. Cyclin D suppression was attributed to both the transcriptional repression and protein degradation assessed by RTPCR and western blotting analysis [56].

Human T-cell leukemia virus type 1 (HTLV-1) infection is responsible for the Adult T-cell leukemia (ATL) which is a fatal malignancy of T lymphocytes [57]. Fucoxanthin isolated from U. pinnatifida and its metabolite, fucoxanthinol, showed inhibitory effect against cell viability of ATL cells as well as HTLV-1-infected T cells without cytotoxicity effect on normal peripheral blood mononuclear cells and uninfected cell lines. However, fucoxanthinol was found to be roughly two times more potent than fucoxanthin. The investigation of the mechanism responsible for this activity showed that decreasing the expression of cdk4, cdk6, cyclin D1, and cyclin D2 in association with upregulation of GADD $45 \alpha$ caused cell cycle arrest at $\mathrm{G}_{1}$ phase [45]. Additionally, activation of caspase-3, caspase8 , and caspase- 9 proved the induction of apoptosis. Nuclear factor- $\kappa \mathrm{B}$ and activator protein-1 were also inactivated due to suppression of $\mathrm{I} \kappa \mathrm{B} \alpha$ phosphorylation and JunD expression. The results were confirmed by in vivo study of fucoxanthinol which caused inhibition of tumor formation in mice with severe combined immunodeficiency harboring tumors induced by inoculation of HTLV-1-infected T cells [45]. 
The antitumor activity by fucoxanthin $(50 \mu \mathrm{M}$ and $75 \mu \mathrm{M})$ and possible mechanisms underlying the inhibitory effect in MGC-803 cells (human gastric adenocarcinoma) revealed dose-dependent elevation in the ratio of cells in $G_{2} / M$ phase and apoptotic cells. This inhibitory effect was associated with significant reduction in the expression of survivin, STAT3 and CyclinB1. The decrease in the expression of CyclinB1 and STAT3 was attenuated by combined treatment of fucoxanthin and AG490 as the inhibitor for JAK/STAT (Janus Kinase/Signal Transducer and Activator of Transcription) signal pathway while the survivin expression was increased. The results indicated the possible role of JAK/STAT signal pathway in the induction of fucoxanthin antitumor activity [58].

Besides direct anticancer activity, the in vitro and ex vivo investigations of fucoxanthin also revealed the antiangiogenic effect of this carotenoid as a complementary potential for cancer prevention. Treatment with fucoxanthin at concentrations greater than $10 \mu \mathrm{M}$ showed significant suppressive effect on the proliferation of human umbilical vein endothelial cells (HUVEC) and tube formation without any significant activity on HUVEC chemotaxis. In addition, 10$20 \mu \mathrm{M}$ concentration of fucoxanthin markedly suppressed the formation and development of blood vessel-like structures from CD31-positive cells using embryonic stem cell-derived embryoid bodies [59]. These results suggest that fucoxanthin can be a potential suppressor of differentiation of endothelial progenitor cells into endothelial cells through disruption in new blood vessel formation. The ex vivo angiogenesis study of fucoxanthin and fucoxanthinol using a rat aortic ring demonstrated suppression of microvessel outgrowth in a dose-dependent manner. The noteworthy angiogenic activity of fucoxanthin might be beneficial for suppression of the cancer aggravation [59]. It is suggested that extensive antitumor activity of fucoxanthin and its metabolites which is summarized in Table 2 is possibly attributed to the presence of 5,6 monoepoxide in the fucoxanthin molecule as one of the contributing factors [60].

\section{Conclusions}

The extensive biological activities mentioned for brown algae include the transcendent anticancer and antitumor effect of fucoidan and fucoxanthin as the two crucial metabolites isolated from various species of Phaeophyceae. Activation of the intrinsic and extrinsic pathway of apoptosis, increase in the immune response, suppression of angiogenesis, and reduction in the adhesion of tumor cells to human platelets are suggested as mechanisms responsible for significant antitumor activity of fucoidan. The superiority of antitumor strength shown by oversulfated fucoidan over natural fucoidan exhibited the critical role of the number of sulfate groups in this molecule. Carotenoid of fucoxanthin and to more extent its metabolite, fucoxanthinol, demonstrated noteworthy antitumor activity associated with the free radical scavenging potential, induction of apoptosis, and the anti-angiogenic effect. It is hoped that this review would be a fountain of motivation and guidance for the interested researchers in conducting further preclinical and clinical studies leading to the development of new chemotherapeutic or chemopreventive agents derived from the metabolites of brown algae.

\section{Conflict of Interests}

The authors declare that they have no conflict of interests.

\section{Acknowledgments}

The authors would like to thank the University of Malaya for providing the research Grant (RP001-2012C) and the High Impact Research (J-21010-73848) and (F000002-21001).

\section{References}

[1] S. Atawodi, "Nigerian foodstuffs with prostate cancer chemopreventive polyphenols," Infectious Agents and Cancer, vol. 6, supplement 2, article S9, 2011.

[2] E. A. Perez, "Impact, mechanisms, and novel chemotherapy strategies for overcoming resistance to anthracyclines and taxanes in metastatic breast cancer," Breast Cancer Research and Treatment, vol. 114, no. 2, pp. 195-201, 2009.

[3] D. Kranz and M. Dobbelstein, "A killer promoting survival: p53 as a selective means to avoid side effects of chemotherapy," Cell Cycle, vol. 11, no. 11, pp. 2053-2054, 2012.

[4] S. Elmore, "Apoptosis: a review of programmed cell death," Toxicologic Pathology, vol. 35, no. 4, pp. 495-516, 2007.

[5] H. F. Ji, X. J. Li, and H. Y. Zhang, "Natural products and drug discovery: can thousands of years of ancient medical knowledge lead us to new and powerful drug combinations in the fight against cancer and dementia?" EMBO Reports, vol. 10, no. 3, pp. 194-200, 2009.

[6] H. Yang, M. Zeng, S. Dong, Z. Liu, and R. Li, "Anti-proliferative activity of phlorotannin extracts from brown algae Laminaria japonica Aresch," Chinese Journal of Oceanology and Limnology, vol. 28, no. 1, pp. 122-130, 2010.

[7] R. Pangestuti and S. K. Kim, "Biological activities and health benefit effects of natural pigments derived from marine algae," Journal of Functional Foods, vol. 3, no. 4, pp. 255-266, 2011.

[8] I. Yamamoto and H. Maruyama, "Effect of dietary seaweed preparations on 1,2-dimethylhydrazine-induced intestinal carcinogenesis in rats," Cancer Letters, vol. 26, no. 3, pp. 241-251, 1985.

[9] I. Yamamoto, H. Maruyama, and M. Moriguchi, “The effect of dietary seaweeds on 7,12-dimethyl-benz[a]anthracene-induced mammary tumorigenesis in rats," Cancer Letters, vol. 35, no. 2, pp. 109-118, 1987.

[10] N. Bourgougnon, C. Roussakis, J. M. Kornprobst, and M. Lahaye, "Effects in vitro of sulfated polysaccharide from Schizymenia dubyi (Rhodophyta, Gigartinales) on a non-smallcell bronchopulmonary carcinoma line (NSCLC-N6)," Cancer Letters, vol. 85, no. 1, pp. 87-92, 1994.

[11] A. M. S. Mayer and K. R. Gustafson, "Marine pharmacology in 2000: antitumor and cytotoxic compounds," International Journal of Cancer, vol. 105, no. 3, pp. 291-299, 2003.

[12] S. B. Khan, C. S. Kong, J. A. Kim, and S. K. Kim, "Protective effect of amphiroa dilatata on ROS induced oxidative damage and MMP expressions in HT1080 cells," Biotechnology and Bioprocess Engineering, vol. 15, no. 1, pp. 191-198, 2010. 
[13] A. Asai, T. Sugawara, H. Ono, and A. Nagao, "Biotransformation of fucoxanthinol into amarouciaxanthin a in mice and HepG2 cells: formation and cytotoxicity of fucoxanthin metabolites," Drug Metabolism and Disposition, vol. 32, no. 2, pp. 205-211, 2004.

[14] M. J. Kwon and T. J. Nam, "Porphyran induces apoptosis related signal pathway in AGS gastric cancer cell lines," Life Sciences, vol. 79, no. 20, pp. 1956-1962, 2006.

[15] M. Zubia, M. S. Fabre, V. Kerjean et al., "Antioxidant and antitumoural activities of some Phaeophyta from Brittany coasts," Food Chemistry, vol. 116, no. 3, pp. 693-701, 2009.

[16] E. Taskin, Z. Caki, M. Ozturk, and E. Taskin, "Assessment of in vitro antitumoral and antimicrobial activities of marine algae harvested from the eastern Mediterranean sea," African Journal of Biotechnology, vol. 9, no. 27, pp. 4272-4277, 2010.

[17] Y. Athukorala, K. N. Kim, and Y. J. Jeon, "Antiproliferative and antioxidant properties of an enzymatic hydrolysate from brown alga, Ecklonia cava," Food and Chemical Toxicology, vol. 44, no. 7, pp. 1065-1074, 2006.

[18] H. Noda, H. Amano, K. Arashima, and K. Nisizawa, "Antitumor activity of marine algae," in Proceedings of the 13th International Seaweed Symposium, pp. 577-584, Springer, 1990.

[19] H. Funahashi, T. Imai, Y. Tanaka et al., "Wakame seaweed suppresses the proliferation of 7,12-dimethylbenz(a)-anthraceneinduced mammary tumors in rats," Japanese Journal of Cancer Research, vol. 90, no. 9, pp. 922-927, 1999.

[20] H. Funahashi, T. Imai, T. Mase et al., "Seaweed prevents breast cancer?” Cancer Science, vol. 92, no. 5, pp. 483-487, 2001.

[21] E. B. Damonte, M. C. Matulewicz, and A. S. Cerezo, "Sulfated seaweed polysaccharides as antiviral agents," Current Medicinal Chemistry, vol. 11, no. 18, pp. 2399-2419, 2004.

[22] A. Cumashi, N. A. Ushakova, M. E. Preobrazhenskaya et al., "A comparative study of the anti-inflammatory, anticoagulant, antiangiogenic, and antiadhesive activities of nine different fucoidans from brown seaweeds," Glycobiology, vol. 17, no. 5, pp. 541-552, 2007.

[23] L. Chevolot, B. Mulloy, J. Ratiskol, A. Foucault, and S. ColliecJouault, "A disaccharide repeat unit is the major structure in fucoidans from two species of brown algae," Carbohydrate Research, vol. 330, no. 4, pp. 529-535, 2001.

[24] T. Teruya, T. Konishi, S. Uechi, H. Tamaki, and M. Tako, "Antiproliferative activity of oversulfated fucoidan from commercially cultured Cladosiphon okamuranus TOKIDA in U937 cells," International Journal of Biological Macromolecules, vol. 41, no. 3, pp. 221-226, 2007.

[25] I. Yamamoto, M. Takahashi, and T. Suzuki, "Antitumor effect of seaweeds. IV. Enhancement of antitumor activity by sulfation of a crude fucoidan fraction from sargassum kjellmanianum," Japanese Journal of Experimental Medicine, vol. 54, no. 4, pp. 143-151, 1984.

[26] D. R. Coombe, C. R. Parish, I. A. Ramshaw, and J. M. Snowden, "Analysis of the inhibition of tumour metastasis by sulphated polysaccharides," International Journal of Cancer, vol. 39, no. 1, pp. 82-88, 1987.

[27] Z. C. Zhuang Cun, H. Itoh, T. Mizuno, and H. Ito, "Antitumor active fucoidan from the brown seaweed, umitoranoo (Sargassum thunbergii)," Bioscience, Biotechnology and Biochemistry, vol. 59, no. 4, pp. 563-567, 1995.

[28] S. Koyanagi, N. Tanigawa, H. Nakagawa, S. Soeda, and H. Shimeno, "Oversulfation of fucoidan enhances its anti-angiogenic and antitumor activities," Biochemical Pharmacology, vol. 65, no. 2, pp. 173-179, 2003.
[29] J. Ye, Y. Li, K. Teruya et al., "Enzyme-digested fucoidan extracts derived from seaweed Mozuku of Cladosiphon novae-caledoniae kylin inhibit invasion and angiogenesis of tumor cells," Cytotechnology, vol. 47, no. 13, pp. 117-126, 2005.

[30] H. Itoh, H. Noda, H. Amano, C. Zhuaug, T. Mizuno, and H. Ito, "Antitumor activity and immunological properties of marine algal polysaccharides, especially fucoidan, prepared from Sargassum thunbergii of phaeophyceae," Anticancer Research, vol. 13, no. 6, pp. 2045-2052, 1993.

[31] H. Maruyama, H. Tamauchi, M. Hashimoto, and T. Nakano, "Antitumor activity and immune response of Mekabu fucoidan extracted from Sporophyll of Undaria pinnatifida," In Vivo, vol. 17, no. 3, pp. 245-249, 2003.

[32] T. V. Alekseyenko, S. Y. Zhanayeva, A. A. Venediktova et al., "Antitumor and antimetastatic activity of fucoidan, a sulfated polysaccharide isolated from the Okhotsk sea Fucus evanescens brown alga," Bulletin of Experimental Biology and Medicine, vol. 143, no. 6, pp. 730-732, 2007.

[33] D. Riou, S. Colliec-Jouault, D. Pinczon Du Sel et al., "Antitumor and antiproliferative effects of a fucan extracted from ascophyllum nodosum against a non-small-cell bronchopulmonary carcinoma line," Anticancer Research, vol. 16, no. 3, pp. 12131218, 1996.

[34] Y. Aisa, Y. Miyakawa, T. Nakazato et al., "Fucoidan induces apoptosis of human HS-Sultan cells accompanied by activation of caspase-3 and down-regulation of ERK pathways," American Journal of Hematology, vol. 78, no. 1, pp. 7-14, 2005.

[35] H. Kawamoto, Y. Miki, T. Kimura et al., "Effects of fucoidan from Mozuku on human stomach cell lines," Food Science and Technology Research, vol. 12, no. 3, pp. 218-222, 2006.

[36] Y. Yamasaki-Miyamoto, M. Yamasaki, H. Tachibana, and K. Yamada, "Fucoidan induces apoptosis through activation of caspase-8 on human breast cancer MCF-7 cells," Journal of Agricultural and Food Chemistry, vol. 57, no. 18, pp. 8677-8682, 2009.

[37] M. I. Bilan, A. A. Grachev, N. E. Ustuzhanina, A. S. Shashkov, N. E. Nifantiev, and A. I. Usov, "A highly regular fraction of a fucoidan from the brown seaweed Fucus distichus L.," Carbohydrate Research, vol. 339, no. 3, pp. 511-517, 2004.

[38] E. J. Kim, S. Y. Park, J. Y. Lee, and J. H. Y. Park, "Fucoidan present in brown algae induces apoptosis of human colon cancer cells," BMC Gastroenterology, vol. 10, article 96, 2010.

[39] J. H. Hyun, S. C. Kim, J. I. Kang et al., "Apoptosis inducing activity of fucoidan in HCT-15 colon carcinoma cells," Biological and Pharmaceutical Bulletin, vol. 32, no. 10, pp. 1760-1764, 2009.

[40] A. Synytsya, W. J. Kim, S. M. Kim et al., "Structure and antitumour activity of fucoidan isolated from sporophyll of Korean brown seaweed Undaria pinnatifida," Carbohydrate Polymers, vol. 81, no. 1, pp. 41-48, 2010.

[41] M. Hejna, M. Raderer, and C. C. Zielinski, "Inhibition of metastases by anticoagulants," Journal of the National Cancer Institute, vol. 91, no. 1, pp. 22-36, 1999.

[42] A. Philchenkov, M. Zavelevich, T. Imbs, T. Zvyagintseva, and T. Zaporozhets, "Sensitization of human malignant lymphoid cells to etoposide by fucoidan, a brown seaweed polysaccharide," Experimental Oncology, vol. 29, no. 3, pp. 181-185, 2007.

[43] G. van Poppel and H. van den Berg, "Vitamins and cancer," Cancer Letters, vol. 114, no. 1-2, pp. 195-202, 1997.

[44] S. K. Das, T. Hashimoto, K. Shimizu et al., "Fucoxanthin induces cell cycle arrest at G0/G1 phase in human colon carcinoma cells through up-regulation of $p 21^{\mathrm{WAF} 1 / \mathrm{Cipl}}$, , Biochimica et Biophysica Acta, vol. 1726, no. 3, pp. 328-335, 2005. 
[45] C. Ishikawa, S. Tafuku, T. Kadekaru et al., "Antiadult T-cell leukemia effects of brown algae fucoxanthin and its deacetylated product, fucoxanthinol," International Journal of Cancer, vol. 123, no. 11, pp. 2702-2712, 2008.

[46] J. Okuzumi, H. Nishino, M. Murakoshi et al., "Inhibitory effects of fucoxanthin, a natural carotenoid, on $\mathrm{N}$-myc expression and cell cycle progression in human malignant tumor cells," Cancer Letters, vol. 55, no. 1, pp. 75-81, 1990.

[47] J. Okuzumi, T. Takahashi, T. Yamane et al., "Inhibitory effects of fucoxanthin, a natural carotenoid, on $\mathrm{N}$-ethyl- $\mathrm{N}^{\prime}$-nitroN-nitrosoguanidine-induced mouse duodenal carcinogenesis," Cancer Letters, vol. 68, no. 2-3, pp. 159-168, 1993.

[48] H. Nishino, "Cancer prevention by carotenoids," Mutation Research, vol. 402, no. 1-2, pp. 159-163, 1998.

[49] J. M. Kim, S. Araki, D. J. Kim et al., "Chemopreventive effects of carotenoids and curcumins on mouse colon carcinogenesis after 1,2-dimethylhydrazine initiation," Carcinogenesis, vol. 19, no. 1, pp. 81-85, 1998.

[50] M. Hosokawa, S. Wanezaki, K. Miyauchi et al., "Apoptosisinducing effect of fucoxanthin on human leukemia cell line HL60," Food Science and Technology Research, vol. 5, no. 3, pp. 243246, 1999.

[51] E. Kotake-Nara, M. Kushiro, H. Zhang, T. Sugawara, K. Miyashita, and A. Nagao, "Carotenoids affect proliferation of human prostate cancer cells," Journal of Nutrition, vol. 131, no. 12, pp. 3303-3306, 2001.

[52] M. Hosokawa, M. Kudo, H. Maeda, H. Kohno, T. Tanaka, and K. Miyashita, "Fucoxanthin induces apoptosis and enhances the antiproliferative effect of the PPAR $\gamma$ ligand, troglitazone, on colon cancer cells," Biochimica et Biophysica Acta, vol. 1675, no. 13, pp. 113-119, 2004.

[53] E. Kotake-Nara, A. Asai, and A. Nagao, "Neoxanthin and fucoxanthin induce apoptosis in PC-3 human prostate cancer cells," Cancer Letters, vol. 220, no. 1, pp. 75-84, 2005.

[54] E. Kotake-Nara, T. Sugawara, and A. Nagao, "Antiproliferative effect of neoxanthin and fucoxanthin on cultured cells," Fisheries Science, vol. 71, no. 2, pp. 459-461, 2005.

[55] S. Yoshiko and N. Hoyoko, "Fucoxanthin, a natural carotenoid, induces G1 arrest and GADD45 gene expression in human cancer cells," In Vivo, vol. 21, no. 2, pp. 305-309, 2007.

[56] S. K. Das, T. Hashimoto, and K. Kanazawa, "Growth inhibition of human hepatic carcinoma HepG2 cells by fucoxanthin is associated with down-regulation of cyclin D," Biochimica et Biophysica Acta, vol. 1780, no. 4, pp. 743-749, 2008.

[57] Y. Hinuma, K. Nagata, and M. Hanaoka, "Adult T-cell leukemia: antigen in an ATL cell line and detection of antibodies to the antigen in human sera," Proceedings of the National Academy of Sciences of the United States of America, vol. 78, no. 10, pp. 64766480, 1981.

[58] R. X. Yu, X. M. Hu, S. Q. Xu, Z. J. Jiang, and W. Yang, "Effects of fucoxanthin on proliferation and apoptosis in human gastric adenocarcinoma MGC-803 cells via JAK/STAT signal pathway," European Journal of Pharmacology, vol. 657, no. 13, pp. 10-19, 2011.

[59] T. Sugawara, K. Matsubara, R. Akagi, M. Mori, and T. Hirata, "Antiangiogenic activity of brown algae fucoxanthin and its deacetylated product, fucoxanthinol," Journal of Agricultural and Food Chemistry, vol. 54, no. 26, pp. 9805-9810, 2006.

[60] P. K. Duitsman, A. B. Barua, B. Becker, and J. A. Olson, "Effects of epoxycarotenoids, $\beta$-carotene, and retinoic acid on the differentiation and viability of the leukemia cell line NB4 in vitro," International Journal for Vitamin and Nutrition Research, vol. 69 , no. 5, pp. 303-308, 1999. 


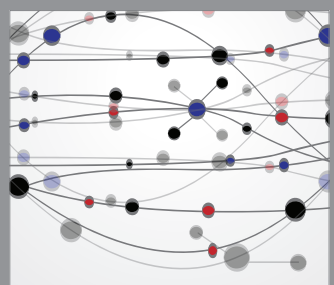

The Scientific World Journal
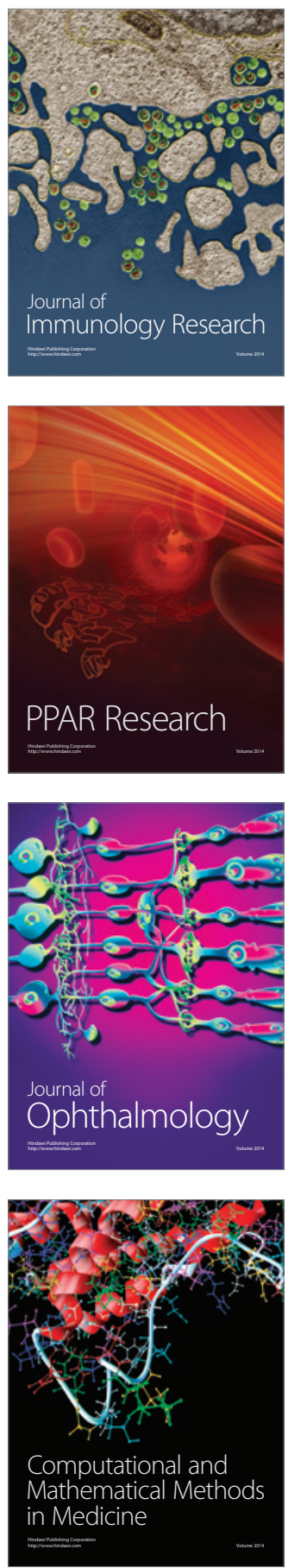

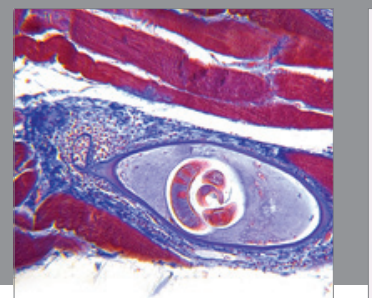

Gastroenterology

Research and Practice
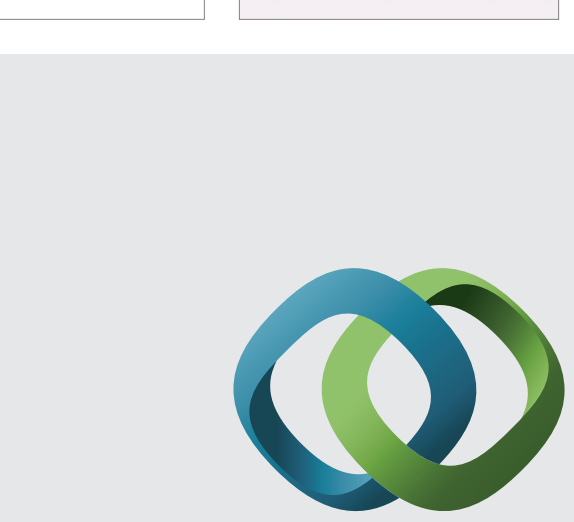

\section{Hindawi}

Submit your manuscripts at

http://www.hindawi.com
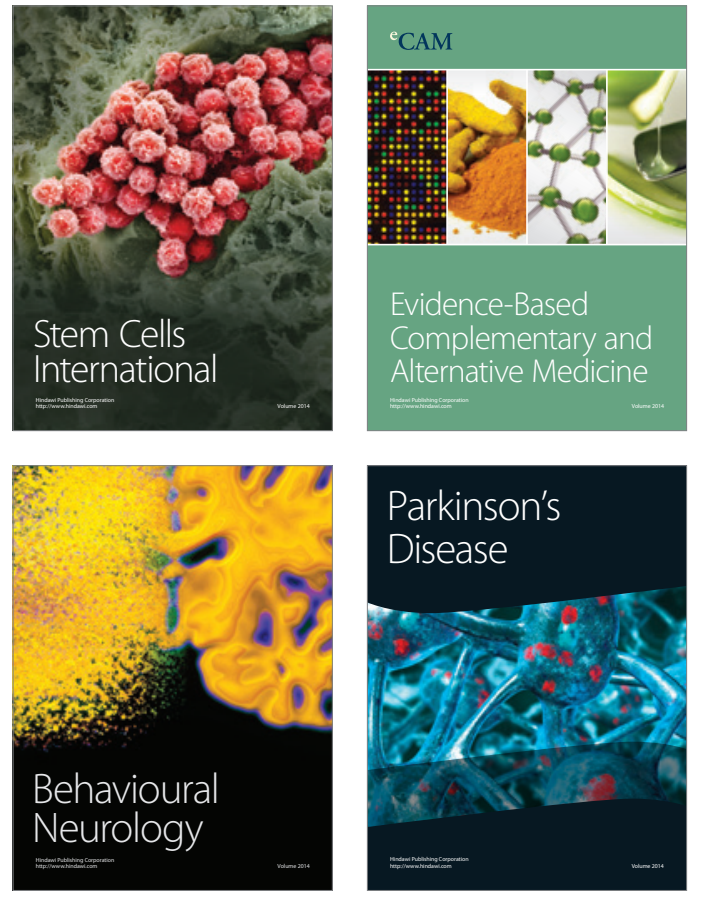
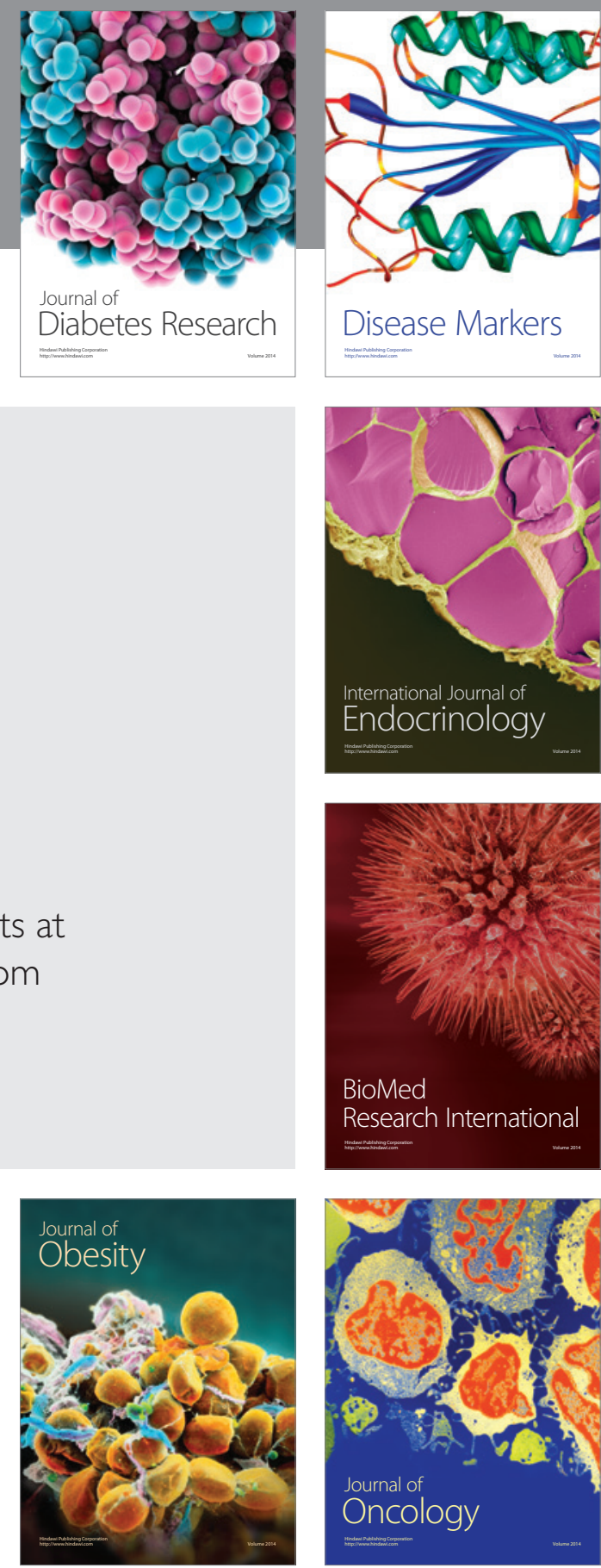

Disease Markers
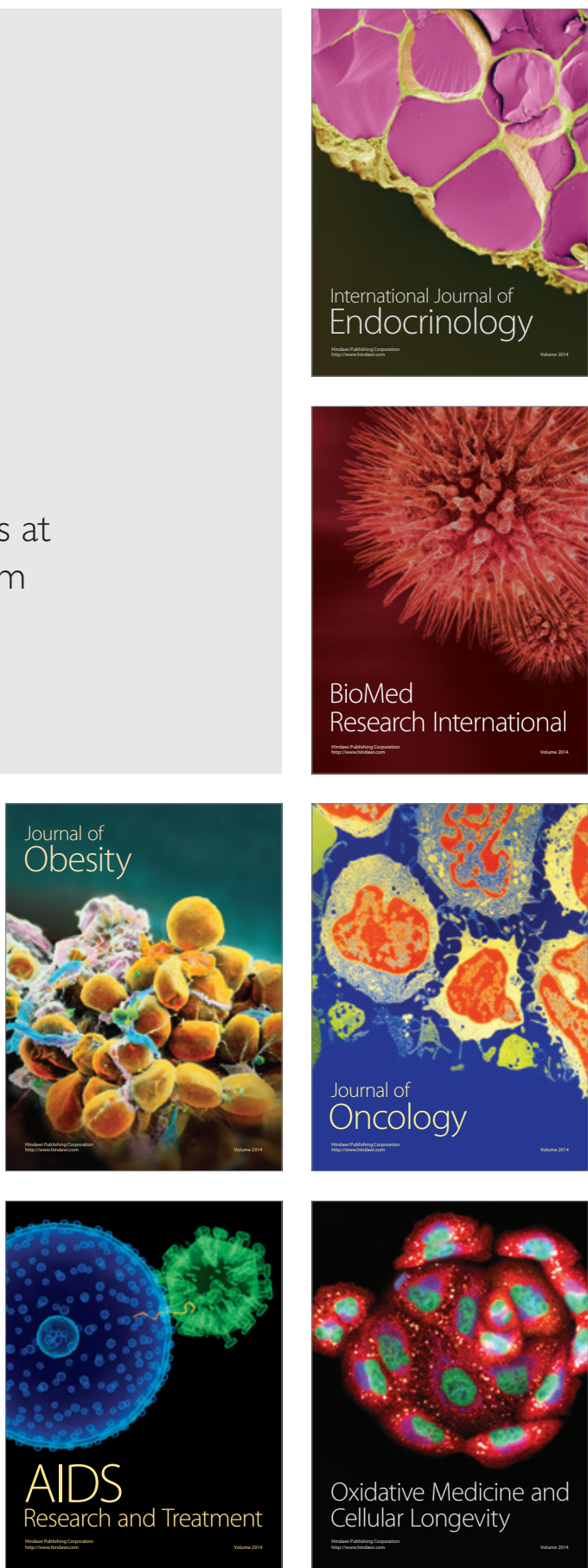